January 2000

\title{
On the Technical Error of the Psychotherapist
}

Satoshi Tamiya M.D.

Menninger Clinic, Topeka, KS

Tetsuro Takahashi M.D.

Ken-lku Kenkyusho, Osaka, Japan

Follow this and additional works at: https://jdc.jefferson.edu/jeffjpsychiatry

Part of the Psychiatry Commons

Let us know how access to this document benefits you

\section{Recommended Citation}

Tamiya, Satoshi M.D. and Takahashi, Tetsuro M.D. (2000) "On the Technical Error of the Psychotherapist," Jefferson Journal of Psychiatry. Vol. 15 : Iss. 1 , Article 5.

DOI: https://doi.org/10.29046/JJP.015.1.007

Available at: https://jdc.jefferson.edu/jeffjpsychiatry/vol15/iss1/5

This Article is brought to you for free and open access by the Jefferson Digital Commons. The Jefferson Digital Commons is a service of Thomas Jefferson University's Center for Teaching and Learning (CTL). The Commons is a showcase for Jefferson books and journals, peer-reviewed scholarly publications, unique historical collections from the University archives, and teaching tools. The Jefferson Digital Commons allows researchers and interested readers anywhere in the world to learn about and keep up to date with Jefferson scholarship. This article has been accepted for inclusion in Jefferson Journal of Psychiatry by an authorized administrator of the Jefferson Digital Commons. For more information, please contact: JeffersonDigitalCommons@jefferson.edu. 


\title{
On the Technical Error of the Psychotherapist
}

\author{
Satoshi Tamiya, M.D. and Tetsuro Takahashi, M.D.
}

\begin{abstract}
The authors present a psychotherapy case where the therapist's countertransference-based technical error and his way of dealing with it remarkably influenced the course of treatment. The authors emphasize that appropriate training, including supervision and personal psychotherapy or psychoanalysis, is imperative, especially so that the beginning therapist can learn to manage countertransference appropriately. Since technical errors cannot always be avoided, it is important for the therapist to deal with them therapeutically, without feeling ashamed or guilty.
\end{abstract}

\section{INTRODUCTION}

The psychotherapist or psychoanalyst experiences various emotional states, called countertransference, which have the potential to elicit technical errors in the therapy process. This is almost inevitable particularly for an inexperienced therapist. In the following case presentation, we will demonstrate how countertransference was elicited, how it contributed to a technical error in treatment, and how the therapist dealt with the error in a therapeutic way. Although the treatment of this case took place in Japan, we, having practiced psychiatry both in Japan and in the U.S., believe that the issue discussed in this paper is a universal one.

\section{CASE ILLUSTRATION}

Mr. A, a 30-year-old Japanese male living in Japan, sought psychiatric treatment for nausea and emesis. The youngest of three children, he had no family history of mental illness. His paternal grandparents, who were living with his family, had looked after Mr. A and his older brother and sister ever since he was born, because both parents were fishermen, which required them to be absent from the home most of the year.

Mr. A had been experiencing episodes of nausea and emesis periodically since he was about seven years of age. These episodes would occur in public or in situations where he felt tense. After graduating from high school, he left home to work for an electronic company in another city. When he was 20 , he finally sought psychiatric treatment for the nausea and emesis. But he was disappointed with the ineffectiveness of the pharmacotherapy and autogenic training that his physician prescribed, and he left that treatment after only a few sessions. The idea that his symptoms 
might recur and interfere with his work bothered the patient so much, however, that he quit his job and returned to his hometown immediately after the interruption of his first treatment. When he was 27 , he came to this city, where he began a new job as a local public servant. Because his symptoms had not improved, he sought treatment again, this time with one of us (S.T.), who was in the third year of training as a psychotherapist. (The practice of psychoanalytic psychotherapy is less common among Japanese psychiatrists, and psychotherapy supervisors are much less available than in the U.S. As a result, Japanese psychiatrists interested in learning psychotherapy often have to teach themselves. It is therefore the exception rather than the rule that they learn psychotherapy under close, regular supervision. In this case, it was after the therapist had started psychotherapy with $\mathrm{Mr}$. A that he found a supervisor. The therapist of this case was a native Japanese whose primary language was Japanese. The therapy was conducted in Japanese.)

The first three appointments were spent taking the case history. Mr. A's medical history was unremarkable except for a history of inguinal hernia, for which he had undergone surgery as a child, and a more recent duodenal ulcer. A medical work-up had been already done and no identifiable cause of his presenting symptoms had been found. The patient's characteristic personality traits could be seen easily in his orderly demeanor, polite speech, and absolute punctuality. The way he described his life history was abstract, general, and intellectual, which sometimes made the therapist bored and sleepy. These observations, together with the aforementioned life history, gave the therapist the impression that the patient might have an obsessive-compulsive personality. His hypothetical understanding of this case was that the patient's presenting symptoms, namely, nausea and emesis in public situations, were psychosomatic expressions of his anger toward his parents, who he felt had abandoned him. His orderliness and politeness were thought to be a reaction formation of his intense unconscious aggression. Based on this psychodynamic formulation, the therapist recommended that the patient enter psychoanalytic psychotherapy on a weekly basis. Mr. A agreed, and an arrangement was made to meet for 50 minutes weekly in the therapist's outpatient clinic in the university hospital where they had first met. At this point, the therapist told the patient not to make any decisions involving major life changes during therapy. The patient agreed to this requirement.

In the first several sessions, Mr. A talked with a bitter smile and blushed as he described the traumatic childhood memory of his friends laughing at him when they found him licking a piece of candy to alleviate his nausea. He had been so fearful that his relationships with others might break down if his symptoms occurred in interpersonal situations that he could never be as spontaneous as he wanted to be. He also told the therapist that he had been refusing any arranged meetings to consider marriage (a common, century-old Japanese custom) because his symptoms made him feel so inferior and worthless, and because he was afraid that they might be hereditary. During this beginning phase, the patient did not cancel any sessions and was never tardy.

In the 11 th session (14th week), Mr. A reported to the therapist that, for the first 
time in his life, he had arranged a meeting for marriage consideration. He stated that he had done so because the therapist had indicated that his symptoms were not hereditary. Listening to the patient, the therapist thought, "Didn't I tell you not to make any major life changes?!" and felt angry with the patient. Although the patient's noncompliance irritated him, the therapist said nothing at this point. Later in the same session, the patient revealed that he had been using candy to alleviate his symptoms in the therapy sessions, too. The therapist instantly understood this behavior as the patient's acting-out in the session. Without discussing this understanding with the patient, the therapist told him to stop it and to postpone any marriage plan until after the termination of therapy. The therapist was not aware of the role his anger played in this intervention. The patient did not oppose the prohibition against candy, but toward the end of this session said, "How long do you think it will take to get better? I can't be absent from my job so often for this therapy," as if to threaten the therapist with ending the therapy.

Dramatic changes then began to occur. As directed, Mr. A came to the next session without candy in his mouth, which caused him to gag in the session for the first time. The emesis continued from then on. The most remarkable change, though, was that the patient began to cancel sessions frequently. There were in fact 11 cancellations in the following 9 months. Mr. A was also often tardy, and would fall silent during sessions. When he did talk, he often expressed disappointment with the ongoing therapy. He said to the therapist, "I have found no effect so far," and, "This therapy annoys me." In addition, associations triggered by the prohibition of candy began to appear: "I don't know what to do when I feel nausea." "I felt very anxious when told to stop using candy. It was not so easy to stop it." "It's hard to change an established pattern." But the therapist did not pick up on these associations, and was unable to understand their importance. He did not even notice that all of these changes began immediately after the 11 th session, the one in which he told the patient not to use candy.

It was at this point that the therapist was finally able to find an experienced psychotherapist (T.T.) as his supervisor through a colleague's referral. (The supervisor was a native Japanese who then practiced general psychiatry and psychoanalytic psychotherapy in the U.S. The supervision was conducted weekly in Japanese through international fax. The therapist sent the process note of each therapy session to the supervisor, who wrote back his comments and discussion. Supervision through fax may be an interesting topic that merits a separate discussion, but we do not intend to touch upon this point in this paper.) And it was only after he began to be supervised on a regular basis, from the 28th session (42nd week) on, that the therapist realized that his prohibition of candy, without discussing it with the patient, was a technical error, and that it was imperative to deal with it in the following sessions. When the supervisor pointed out the error, the therapist felt ashamed and guilty. These feelings of shame and guilt hindered him from discussing the error with the patient, and he did not do so until the 35 th session.

Finally, in the 35th session (56th week), Mr. A said, "This therapy has helped me realize that it's impossible to change oneself at once." For the first time, the therapist 
connected this association with the prohibition of candy and discussed the issue with the patient. Although still feeling guilty about his technical error and ashamed of acknowledging it, the therapist consciously dealt with the issue every time the related associations appeared in the following sessions, and explored the patient's response to his technical error. This procedure helped the therapist realize that the patient was expressing his conflict when he said, "I can't help but try to adapt myself to others. I don't want to make others uncomfortable by opposing them. On the other hand, I do want to be assertive." Mr. A also said to the therapist, "I used to feel sorry for you if I felt nausea during these hours. But even when I did so, you were just looking at me without saying anything. It was a strange experience for me." This comment showed that the patient had begun to understand, through a corrective emotional experience, that he could be himself and that his symptoms would not destroy his interpersonal relationships. Although his symptoms continued to appear in the following sessions, he canceled only one meeting after the 35 th session. The therapy came to an end after the 48th session (72nd week) because the therapist had to move to another hospital. The patient's case was then transferred to another therapist. Reviewing this case after termination, the therapist realized for the first time that the patient's cancellations were scattered only between the 11th and 35th sessions, namely, from the initial prohibition of using candy until the discussion of the technical error.

\section{DISCUSSION}

In the literature on psychoanalysis and psychoanalytic psychotherapy, there has been increasing recognition that the materials produced in the course of treatment derive not only from the patient but also from the therapist, as well as from the patient's and the therapist's interactions. For example, Ogden (1) states:

In an analytic context, there is no such thing as an analysand apart from the relationship with the analyst, and no such thing as an analyst apart from the relationship with the analysand. ... The intersubjective and the individually subjective each create, negate, and preserve the other. (pp. 63-64)

The technical implication of this statement is that the psychoanalyst or the psychotherapist has to constantly examine his or her own contribution to the treatment process. The clearest example of this is a technical error, because it is obvious that such an error is the therapist's contribution, not the patient's. Every therapist makes mistakes and thus must be aware of how they can influence treatment. Although they may not be as conspicuous as beginners' mistakes, experienced analysts or therapists may make mistakes, too.

Many authors have discussed the psychoanalyst's or psychotherapist's technical errors. Greenson (2), for example, described three categories of technical error: 1) "occasional errors," 2) "errors due to prolonged countertransference interference," and 3) "other protracted errors in technique," including "lack of clinical knowledge," 
"faulty theoretical knowledge," and "cultural unfamiliarity with a type of person." Especially relevant to our discussion is his statement that "the error has to be acknowledged openly, but this acknowledgement should be used to get further material from the patient, not to appease or neutralize the patient's reaction" ( $p$. 347). Langs (3) seems to be in complete agreement when he states that "the major problem in such a situation-except for extreme trauma-is not so much the initial error made by the therapist, as his failure to recognize and subsequently to deal with it" (p. 311). We will touch on this point again later.

Langs (3) also comments on how to recognize the therapist's error and the patient's response to it:

The appearance of regressions in the patient and disruptions in the therapeutic alliance should alert the therapist first to reassess his interventions - or failures to intervene-his general attitude toward the patient, and other aspects of his therapeutic stance for countertransference difficulties. (p. 310)

It was these "countertransference difficulties" that led to the therapist's technical error in the presented case, as we will discuss further. Now, however, we will turn to the issue of countertransference.

According to Langs (3), there are 14 "types of hostile countertransference expressions." One of them, "unnecessarily frustrating the patient," may be relevant to our case, because the therapist's prohibition of candy severely frustrated the patient.

Langs classifies 8 types of "common responses in patients to hostile countertransferences." Four of them, 1) "attacking and criticizing the therapist and therapy, and disruptions of the therapeutic alliance," 2) "wanting to leave, or actually leaving, therapy," 3) "other forms of acting out and acting in," and 4) "intensification of symptoms and other regressions" (pp. 358-359), may be relevant to our case. For example, after the prohibition of candy, the patient began complaining about the therapy, being late for or canceling sessions, and showing symptoms in the sessions.

Blau (4) classifies therapist factors that contribute to the technical error as 1) errors of inadequate training or experience, 2) neurotic psychotherapy errors, and 3) errors of character pathology. Some examples are given for each factor. For our case, the first factor can be considered relevant, as well as a subcategory of the second factor, "becoming angry or inappropriately confrontative."

Thus the interaction between Mr. A and the therapist may be understood in the following way: The therapist was inexperienced and was not supervised at the beginning of this treatment. In addition, he did not have any personal experience of psychotherapy or psychoanalysis. When he realized that the patient was considering marriage against his direction, he became angry with the patient. This anger might well have stemmed from his unconscious wish to control the patient and exert power over him, and he acted on this countertransference feeling by depriving the patient of candy. Furthermore, the therapist rationalized his own acting-out, regarding it as appropriate limitsetting in response to the patient's acting-out. The patient might 
have experienced the therapist's reaction in a similar traumatic way as he had experienced his childhood friends' reactions when they learned about his candy. The patient then responded to the therapist by showing his symptoms in the sessions or by frequent silence, tardiness, and cancellations. This situation generated the hidden tension between the two, which persisted until the 35 th session, in which the therapist finally addressed this issue for the first time. The tension was then reduced, resulting in much fewer cancellations and less tardiness by the patient. Furthermore, the therapist's understanding of the patient's psychodynamics was enhanced by exploring in supervision his responses to the therapist's error.

Although it is important for therapists to avoid making any technical errors, the success of treatment also depends on how they deal with an error that does occur. To handle such an error, therapists require enough training, including supervision, because the countertransference reaction and its acting-out originally derive from the therapist's unconscious. As Freud (5) noted, acting-out occurs instead of remembering (i.e. thinking). Moreover, countertransference reactions may be rationalized by the therapist, as in this case. Jacobs (6) explains that it is these subtle countertransference reactions that are "so easily rationalized as parts of our standard operating procedures and so easily overlooked, [and] that may in the end have the greatest impact on our analytic work" (pp. 155-156). Unnoticed countertransference may do much harm to treatment. Jacobs (6) reminds us that "enactments are carried out before the wishful elements that motivate them reach consciousness" (p. 32).

To resolve these issues, Blau (4) recommends 1) reading, workshops, and supervision to resolve errors of inadequate training or experience; 2) consultation with an experienced colleague, as well as psychotherapy for the psychotherapist to resolve neurotic psychotherapeutic errors; and 3) transfer of the patient to an experienced, interested, and willing colleague, with full disclosure, and rehabilitation and preventive restraints for the therapist to resolve character-based psychotherapeutic errors.

Dewald (7) emphasizes "an increasing capacity for self-analysis, allowing recognition and acceptance of countertransference factors" (p. 12) as one of the goals of supervision. The therapist of the presented case recognized his anger toward the patient only when it was pointed out by his supervisor. Similarly, only when he reviewed the process of treatment after its termination, did he realize the sequential relationships of his anger and his prohibition of the patient's candy in the 11th session, the changes in the patient's attitude that followed, and the discussion about them in the 35 th session. Furthermore, it was even later, in his personal analysis, that he gained insight into his conflict related to control and power.

We should especially emphasize the importance of the "constructive" use of the therapist's technical error as Greenson (2) and Langs (3) suggest. Everything that happens in treatment should be explored. The therapist's technical error and the patient's response to it are not exempt from this rule. As Langs states, "The reaction of the patient should be allowed to unfold" (p. 363), and "this problem takes precedence over all other topics and therapeutic contexts, except, of course, for 
emergencies" (p. 363). In the case we have, this exploration led both parties to a new understanding and paved the way for further therapeutic benefit to the patient.

Before closing our discussion, we have one final point to make. The therapist made a technical error, not an ethical one, let alone a criminal one. The therapist does not have to apologize and should not feel excessively guilty about the error when exploring it, which may well be another countertransference issue. Greenson (2) states:

I made no formal apology about the mistake of mine described above because it was not one of etiquette, nor did it involve a breach of good conduct. I was technically wrong about something, not guilty; I was sorry I caused undue pain, but these are the hazards of treatment and have to be reckoned with. (p. 347)

A beginning therapist is more prone to feel guilty about mistakes than an experienced therapist because, from the start, the beginner usually already feels guilty for having less experience. Of course, being a beginner does not mean that the therapist is doing something evil. But he or she is responsible for seeking consultation or supervision, and for making good use of it, which can compensate for the shortage of experience and knowledge.

\section{ACKNOWLEDGEMENT}

We wish to thank Alice Brand Bartlett, MLS, for reviewing the manuscript and Mr. Philip Beard and Mrs. Mary Ann Clifft for their editorial help in preparation of the manuscript.

\section{REFERENCES}

1. Ogden T: Subjects of analysis. Northvale, Jason Aronson, 1994.

2. Greenson R: The technique and practice of psychoanalysis: Vol. 1. New York, International Universities Press, 1967.

3. Langs R: The technique of psychoanalytic psychotherapy: Vol. 2. Northvale, Jason Aronson, 1974.

4. Blau T: Psychotherapy tradecraft: The technique and style of doing therapy. New York, Brunner/Mazel, 1988.

5. Freud S: Remembering, repeating and working-through. In StracheyJ (Ed. and Trans.), The standard edition of the complete psychological works of Sigmund Freud: Vol. 12. London, Hogarth Press, 1958. (Original work published 1914)

6. Jacobs T: The use of the self: Countertransference and communication in the analytic situation. New York, International Universities Press, 1991.

7. Dewald P: Learning process in psychoanalytic supervision: Complexities and challenges. New York, International Universities Press, 1987. 